\title{
ESPAÇO DE ENUNCIAC̣ÃO DA LÍNGUA DE IMIGRAÇÃO ALEMÃ: O FUNCIONAMENTO POLÍTICO DA RELIGIÃO COMO LUGAR DE MEMÓRIA
}

\author{
SPEAKING SPACE OF THE GERMAN IMMIGRATION LANGUAGE: THE POLITICAL \\ FUNCTIONING OF RELIGION AS A PLACE OF MEMORY
}

\author{
Rejane Fiepke Carpenedo ${ }^{1}$ \\ Eliana Rosa Sturza ${ }^{2}$
}

\begin{abstract}
RESUMO: Este estudo é parte da pesquisa de tese que está em andamento, em que a proposta é pesquisar a língua de imigração alemã, escrita e falada, no município de Novo Machado - RS à luz dos estudos enunciativos. O objetivo deste artigo é refletir acerca do funcionamento político do espaço de enunciação religioso como lugar de memória da língua, pensado a partir da teoria da Enunciação, com base na Semântica do Acontecimento (GUIMARÃES, 2002). O corpus mobilizado constitui-se de fotografias como materialidade de registro dos enunciados em língua alemã, para fins de possibilitar a análise dos espaços de enunciação. Observa-se que o discurso religioso constitui-se como um lugar de memória da língua, e se faz presente nos espaço de enunciação públicos e privados. Isto evidencia que a língua de imigração marca o seu funcionamento como lugar de pertencimento do sujeito, inscrevendo-se nas mais distintas instâncias da vida dos descendentes de alemães.
\end{abstract}

Palavras-chave: Língua de imigração alemã; memória; enunciação.

ABSTRACT: This study is part of our ongoing thesis research, in which we propose to research the written and spoken German immigration language in the municipality of Novo Machado - RS in the light of the enunciative studies. The aim of this article is to reflect on the of political functioning space of religious enunciation as a place of memory of the language, thought from the theory of Enunciation, based on the Semantics of the Event (GUIMARÃES, 2002). The mobilized corpus consists of photographs as materiality for registering the utterances in German, in order to enable the analysis of the enunciation spaces. We observe that the religious discourse constitutes a place of memory of the language, and is present in public and private enunciation spaces. This shows that the language of immigration marks its functioning as a place of belonging to the subject, inscribing itself in the most distinct instances of the life of the descendants of Germans.

Keywords: German immigration language; memory; enunciation.

\footnotetext{
${ }^{1}$ Doutoranda em Letras pelo Programa de Pós-Graduação em Letras da Universidade Federal de Santa Maria UFSM. Bolsista CAPES.

2 Doutora em Linguística pela Universidade Estadual de Campinas - UNICAMP. Professora Associada da Universidade Federal de Santa Maria - UFSM. Coordenadora do Programa de Pós-graduação em Letras - UFSM.
} 


\section{Memórias da língua que constituem o sujeito}

Na casa da oma ${ }^{3}$, depois do almoço de domingo a louça era secada com um pano de prato pintado a mão, em que estava escrito "Der Herr ist mein Hirte, mir wird nichts mangeln.". Sobre a tampa do fogão havia outro pano estendido que dizia "Sonntag", e na parede um lindo wandschoner ${ }^{5}$ antigo bordado em letra gótica, anunciando "Ich aber und mein Haus, wir wollen dem Herrn dienen! Josua 24,15". Sobre a mesa, um delicado vaso de flores colhidas no jardim, e um livro de capa preta que dizia "Die Heilige Schrift". E, pelo menos uma vez ao ano quando a família levava flores aos seus entes no cemitério, diante de uma lápide com a inscrição "Hier ruht in frieden ${ }^{8}[. .$.$] ", alguém falava: "aqui descansa o teu bisavô", de quem havia poucas recordações$ nas lembranças de uma criança.

Estas memórias dispersas talvez não significassem muito à autora no momento em que foram constituídas, pois não passavam de detalhes do cotidiano de uma guria de família de imigrantes e descendentes de alemães. Hoje, elas inquietam, porque estão imersas em sentidos que podem ser tocados com o valer do pensar científico. Hoje são mais que apenas panos bonitos com dizeres, e lápides com inscrições na língua que todos falavam em casa. São funcionamentos políticos em espaços de enunciação.

E assim, esta pesquisa surge de memórias fragmentadas, que constituem o sujeito, e uma reflexão e busca sobre os estudos que já existem referentes à temática. Onde mais poderá haver panos bonitos escritos em alemão como os da casa da oma? E, será que não há coisas e espaços muito além de panos e lápides enunciando uma memória de pertencimento à língua? É isto que queremos investigar.

A realização desta pesquisa se justifica cientificamente por se apresentar como um estudo pouco recorrente no campo enunciativo, por mobilizar fotografias da escrita da língua como materialidade enunciativa para objeto de análise, e ser uma investigação sobre o status atual da língua de imigração alemã escrita no município de Novo Machado - RS.

Ainda, este estudo se vincula a nossa pesquisa de mestrado, desenvolvida a partir da temática "A língua no discurso do senso comum: ideologia e imaginário", em que os resultados apontam para a existência de um imaginário fortemente marcado no senso comum de que o Brasil é um país de homogeneidade linguística. De encontro a isso, a pesquisa que está em desenvolvimento no doutorado se propõe a apresentar um estudo a partir de uma, das tantas, línguas de imigração que ainda coexistem com a língua portuguesa em solo nacional, refutando a ideia de que "todos falam a mesma língua e da mesma forma".

As línguas de imigração e políticas linguísticas tem sido objeto de diferentes estudos no campo da linguística. A citar alguns trabalhos mais conhecidos, temos Maria Onice Payer (2009) e Carmen Zink Bolognini (2005), voltando-se à memória da língua de imigração italiana e à nacionalidade; Vejane Gaelzer (2014), que reflete acerca das relações entre identidade, memória e história a partir de construções imaginárias e discursivas de sujeitos descendentes de imigrantes alemães; trabalhos estes, pensados na perspectiva da Análise de Discurso Francesa.

\footnotetext{
${ }^{3}$ Tradução: Avó.

${ }^{4}$ Tradução: O senhor é o meu pastor e nada me faltará.

${ }^{5}$ Tradução: Protetor de parede. Termo usado para os panos de parede.

${ }^{6}$ Tradução: Eu e a minha casa queremos servir ao Senhor. Josué 24:15".

${ }^{7}$ Tradução: Sagradas Escrituras.

${ }^{8}$ Tradução: Aqui descansa em paz.
} 
Há também pesquisas desenvolvidas no Programa de Pós-Graduação em Letras (PPGL) da Universidade Federal de Santa Maria (UFSM), a citar Juciane Ferigolo Parcianello (2011), que em sua dissertação de mestrado abordou a memória discursiva e as fronteiras enunciativas, a partir de entrevistas com sujeitos descendentes de imigrantes italianos na região da Quarta Colônia; Viviane Brust (2013), que pensa a memória da imigração italiana na Quarta Colônia a partir de outra materialidade, os monumentos ao imigrante.

Neste sentido, nosso objetivo é pensar como a língua de imigração circula hoje, quais memórias a perpassam, em quais os espaços ela está destinada a ser usada em sua forma escrita, e como se dá a disputa com a língua portuguesa. Lembrando que esta disputa é política, em que os sujeitos por meio de uma decisão politicamente realizada optam qual a língua irá ocupar estes espaços. Ao realizar os primeiro movimentos de constituição do corpus, observamos que um dos espaços de enunciação mais recorrentes é o religioso, e é este que buscamos analisar neste artigo.

É imprescindível considerar o político no espaço enunciativo, pois o ato de enunciar está inserido em um espaço sócio-histórico, o que por sua vez, irá determinar as ações dos sujeitos, inclusive da fala. Mariani (2004, p. 40), explica as escolhas do sujeito no ato de sua manifestação pela linguagem, afirmando que "Usar uma palavra é não usar outra, é fazer recortes em regiões de sentidos sem ter nenhuma garantia de um entendimento absoluto, é inscrever-se em redes de filiações de sentidos, as memórias e esquecimentos constitutivos do dizer.”. Tamanha é a decisão política, por exemplo, de escolher a língua alemã para o epitáfio da lápide, simbolicamente significado como as últimas palavras dos sujeitos, e que pela inscrição na pedra, permanecem, resistindo ao tempo.

Em uma reflexão inicial somos incitados a pensar também em uma relação de pertencimento identitário que passa pela língua. Nessa perspectiva se observa um pertencimento ao lugar e um pertencimento a língua, e há diferença entre estes, pois em uma lápide com inscrições em alemão em um cemitério no Brasil, há um lugar de memória que se dá pela língua, ou seja, há pertença à língua materna, mas não necessariamente ao lugar. Gaelzer (2011, p.150), em seus estudos discursivos acerca dos imigrantes alemães, afirma que "É pela preservação da língua que se cultivam as memórias, a cultura e o sentimento de pertencimento de um povo.”.

Assim, quando hoje se aproximam os 200 anos da imigração alemã no Brasil e os 80 anos da interdição linguística promovida pelo projeto de Nacionalização da Era Vargas por meio do Decreto-Lei no 406, de 04 de Maio de 1938, nos instiga lançar um olhar sobre uma língua de imigração que sobrevive aos efeitos do tempo, das políticas linguísticas, e da ideologia linguística de um país que crê ser monolíngue. A materialidade enunciativa que mobilizamos, a escrita, que foi amplamente difundida pela religião e pela escola, consiste hoje apenas em memória, ou há quem siga escrevendo a língua? Em que espaços de enunciação estão as memórias da língua, e em que espaços a língua ainda é escrita? Um destes espaços de enunciação é o religioso, que analisamos aqui. Ressaltamos que há uma dupla importância neste estudo: a já referida, de contribuir para o saber científico sobre a língua de imigração alemã; e, de apresentar ao município de Novo Machado um estudo do cenário da língua alemã escrita, língua que representa uma parcela significativa dos sujeitos do lugar.

\section{Pressupostos teórico-metodológicos}


A partir dos pressupostos teórico-metodológicos da teoria da Enunciação, na perspectiva de Guimarães (2002), nos propomos a estudar, por meio de documentos fotográficos, produzidos por nós, quais os espaços de enunciação em que a língua de imigração alemã escrita circula atualmente, e que memória da língua e funcionamentos políticos constituem estes enunciados.

Em decorrência dos vastos estudos sobre a imigração alemã no Brasil, que abrangem principalmente os contatos linguísticos e o período da interdição das línguas durante a Era Vargas, nos desafiamos a investigar os espaços, públicos e privados, em que há enunciados em língua alemã escrita. Por meio de fotografias destes locais/objetos, que segundo a compreensão de Brust (2013) podem ser referidas como documentos fotográficos, procederemos com a análise do corpus construído. Para situar a pesquisa no espaço sócio histórico, destacamos que as fotografias são realizadas no município de Novo Machado, na região noroeste do estado do Rio Grande do Sul, em virtude do fato de ser um município colonizado inicialmente por imigrantes alemães que junto aos seus descendentes prezavam muito pela manutenção da língua, conforme as historiadoras locais Priebe e Schroeder (2005) destacam:

Os imigrantes alemães, talvez mais do que as outras etnias, mantiveram muito fortes as suas tradições e a sua cultura, especialmente, através do cultivo da língua, na própria família, nas práticas religiosas e, da mesma forma, na educação escolar, pois os próprios alemães organizaram suas escolas, administrando-as. (PRIEBE; SCHROEDER, 2005, p. 59).

Assim, compreendemos que os espaços em que circula a língua se constituem como coletivos, religião, comunidade e escola, e privados, no âmbito familiar. Neste sentido, entendemos também que há políticas linguísticas que circunscrevem estes espaços de enunciação, pois ao determinar quais os espaços a língua de imigração alemã escrita irá ocupar, seja por meio de objetos e documentos antigos guardados, ou por registros atuais, há um funcionamento político implicado.

Vale destacar que para este estudo adotamos o conceito de língua referido por Guimarães (2018, p.23), em que "[...] a língua não é algo abstrato, é algo histórico, se apresenta pela prática humana, por relações que fundamentam o funcionamento desta prática cuja característica é a de produzir significações [...]”. Ou seja, ao enunciar por meio da língua o sujeito temporaliza o seu dizer, inscrevendo-o na história.

Conforme Benveniste (2006, p.29), a Linguística é uma ciência que visa "transformar as palavras que voam em uma matéria concreta, que se estuda, que se disseca, onde se delimitam unidades, onde se isolam níveis”. Isso se denomina teoria. Em outras palavras, o mecanismo que permite a concretude e análise de certa matéria. E nesta pesquisa, pretendemos desenvolver uma reflexão a partir da ferramenta teórica e analítica da Semântica do Acontecimento, com foco no conceito de Espaço de Enunciação, pensado por Guimarães (2005), no campo da Teoria da Enunciação. Bem como, é imprescindível que se reflita também acerca do político na enunciação, da memória na língua, e do funcionamento das políticas linguísticas.

Guimarães (2005, p.7) afirma que a Semântica do Acontecimento "constitui uma semântica que considera que a análise do sentido da linguagem se deve localizar no estudo da enunciação, do acontecimento do dizer”. Assim, temos uma semântica linguística com foco na observação do sentido presente no enunciado, pois para o autor, o sentido não é apenas uma relação entre a expressão e o real, e sim, são as relações das formas que significam no 
enunciado. Deste modo, somente podemos compreender o significado de uma forma quando consideramos o seu funcionamento como inerente ao sentido do enunciado.

Saber o que significa uma forma é dizer como seu funcionamento é parte da constituição do sentido do enunciado. Mas para mim, considerar o processo no qual uma forma constitui o sentido de um enunciado é considerar em que medida esta forma funciona num enunciado, enquanto enunciado de um texto. Ou seja, não há como considerar que uma forma funciona em um enunciado, sem considerar que ela funciona num texto, e em que medida ela é constitutiva do sentido do texto. (GUIMARÃES, 2005, p.7)

Compreendemos assim, que não é possível tomar os enunciados isolados de seus textos para estudar os sentidos, uma vez que "A enunciação é tomada como um acontecimento histórico, ou seja, não no sentido da história cronológica, onde os fatos significam um acontecimento social determinado apenas no tempo, sendo, desse modo, um fato sempre único e irrepetível.” (GUIMARÃES, 2002, p.17). Do contrário, é compreendida em um sentido em que a história é constitutiva do presente de uma enunciação, e com isso a sua significação é determinada pelas condições sociais de existência. Por isso, a temporalidade é constituída no acontecimento da enunciação.

Partindo dessa particularidade do acontecimento enunciativo, e do seu funcionamento na linguagem, Tatsch (2013), explica como os sentidos são produzidos no entorno do acontecimento enunciativo.

A língua está em constante movimento nesse espaço enunciativo, constituindo, mantendo e atualizando sentidos. Por isso o acontecimento faz surgir o novo, produzindo sentidos pelo funcionamento da língua. Funcionamento esse orientado por uma memória de dizeres sociais, a partir dos quais a língua passa a significar. Nessa perspectiva, o acontecimento enunciativo é permeado por determinações de sentido. (TATSCH, 2013, p. 211).

Guimarães (2005), afirma que para que se tenha um acontecimento é preciso destacar dois elementos que são imprescindíveis para sua realização: a língua e o sujeito na constituição histórica do sentido. Além destes elementos, podemos considerar também que a temporalidade dos acontecimentos é um fator relevante para definir o sentido das formas e expressões e sugerir novos gestos de leitura e novas interpretações. Ressaltando que para que tenhamos um funcionamento discursivo, é fundamental que haja uma materialidade histórica do real, levando em consideração o sujeito físico, que produz as enunciações, bem como, um sujeito, neste caso, o sujeito imigrante ou descendente de imigrantes alemães, que enuncia "[...] afetado pelo simbólico e num mundo vivido através do simbólico.”.

Estes aspectos do acontecimento enunciativo implicam o funcionamento de uma memória da língua, que para Guimarães (1996, p.27) “[...] é uma memória latente, pois para significar precisa confrontar-se sempre com a memória discursiva e o presente do acontecimento. E assim, por ser latente, pode sempre ser outra coisa, para isso bastando que outras enunciações a façam derivar, mesmo que imperceptivelmente". Neste sentido, temos o funcionamento da língua de imigração alemã a partir dos movimentos do interdiscurso, e da 
memória do dizer, ou seja, quando está exposta ao interdiscurso a língua está concomitantemente exposta a uma memória dizível.

Payer (2006) afirma que inerente ao funcionamento da memória da língua, há um funcionamento político, pois a linguagem carrega memórias de sentidos que constituem o modo de significar do sujeito, sobretudo em seu enunciar.

Memórias múltiplas, inscritas em elementos diversos da linguagem, manifestam-se facilmente em situações que se apresentam conflituosas. Este é o caso, quando as línguas junto às memórias que elas trazem, se colocam em contato, entrando em confronto, em diversos contextos específicos de conformidade com as formações sócio-históricas. (PAYER, 2006, p.12)

Em síntese, o sentido é produzido pela enunciação, o que significa dizer que se constitui no e pelo acontecimento do funcionamento da língua. Para Guimarães (2018, p.22) "este acontecimento se apresenta como se dando pela existência de uma língua, porque há falantes que são tomados enquanto falantes pela relação com tal língua.”. Destacando que para o autor o falante não consiste em uma pessoa física, mas "[...] é um lugar de enunciação determinado pela relação com a língua, no que chamamos espaço de enunciação.”. Isto significa que não há línguas sem outras línguas, na mesma proporção que não há línguas sem falantes, e vice-versa.

Um detalhe fundamental na configuração do espaço de enunciação é que as línguas do espaço de enunciação são distribuídas de modo desigual, pois conforme Guimarães (2018, p.24) "[...] não se é falante das línguas deste espaço da mesma maneira. O espaço de enunciação é, então, um espaço político do funcionamento das línguas.”.

Desta forma, percebemos que o político e a enunciação são constitutivos, pois ao enunciar o sujeito significa e com isso se inscreve na história. A Semântica do Acontecimento, teoria adotada nesta pesquisa, se filia ao materialismo histórico, e assim dialoga com o funcionamento do político na linguagem. Weber (2013, p.18) destaca que "para que o político se constitua na língua é preciso haver enunciação".

Quando se fala no lugar do político na linguagem se está afirmando a sua constituição por meio das condições sócio-históricas, e concomitantemente, se assume que a língua está afetada pelas relações sociais. Conforme Orlandi (2002) o político é da ordem do conflito, da diferença, do dissenso, se destacando pela disputa "dos princípios que regem a vida social em suas diferenças, sendo ele próprio a prática dessas diferenças".

Para Guimarães (2002, p. 16) o político na língua é incontrolável, pois “[...] é caracterizado pela contradição de uma normatividade que estabelece (desigualmente) uma divisão do real e a afirmação de pertencimento dos que não estão incluídos.”. Assim, o político enquanto diferença de sentidos "[...] é próprio da divisão que afeta materialmente a linguagem.”. Com isso, os espaços de enunciação da língua de imigração alemã em sua forma escrita, são espaços atravessados pelo funcionamento político, uma vez que significa uma escolha do sujeito ao inscrever o seu pertencimento a uma língua em determinado lugar.

Orlandi (2013) explica a relação da língua e suas respectivas políticas, classificando-as conforme as suas razões.

Falar é uma prática política no sentido amplo, quando se consideram as relações históricas e sociais do poder sempre inscritas na linguagem. Paralelamente a esta forma geral de presença do político na linguagem, nós podemos considerar uma noção mais restrita, mais técnica: é a política das 
línguas ou a política linguística. Pensamos a política linguística a partir de três posições distintas:

1. As políticas linguísticas como razões do Estado, das Instituições que apresentam a questão da unidade como valor (como princípio ético);

2. As políticas linguísticas como razões que regem as relações entre povos, entre nações, Estados: a questão da dominação como valor (como princípio ético);

3. As políticas linguísticas como razões relativas aos que falam as línguas: a questão da diversidade como valor (como princípio ético). (ORLANDI, E, 2013, p.106)

Com isso, compreendemos que os espaços de enunciação de funcionamento da língua de imigração alemã escrita são atravessados por uma política linguística que configura este funcionamento. Nestes espaços ocorre uma disputa de sentidos, significada não necessariamente por uma política linguística de Estado, mas inerente às razões das escolhas linguísticas dos sujeitos. Conforme Guimarães (2018, p.23)

[...] o espaço de enunciação é o espaço de relações linguísticas no qual elas funcionam na sua relação com falantes. Assim, não há línguas sem outras línguas, e não há línguas sem falantes e vice-versa. Um aspecto importante na configuração do espaço de enunciação é que as línguas do espaço de enunciação são distribuídas de modo desigual, não se é falante das línguas deste espaço da mesma maneira. O espaço de enunciação é, então, um espaço político do funcionamento das línguas. (GUIMARÃES, 2018, p.23)

Em um espaço político em que o conflito entre as línguas é constante, a língua de imigração sobrevive. E neste sentido, Brust (2013, p. 56) propõe a língua de areia, como sendo "aquela pela qual a memória da imigração permanece, ainda que fragmentada e dispersa.".

\section{Funcionamento político e memória da língua de imigração: movimento analítico}

O percurso metodológico inicia a partir da nossa materialidade enunciativa, a fotografia, que é pensada enquanto instrumento que constitui o arquivo a ser analisado. Ou seja, a fotografia é o instrumento adotado para o registro dessa materialidade enunciativa, a língua escrita nos espaços de enunciação públicos e privados. Assim, por meio do estudo da literatura já existente em relação à temática, mobilizamos o arcabouço teórico-metodológico da Semântica do Acontecimento, pensado por Guimarães (2002) na perspectiva da Teoria da Enunciação. Desta forma, nos valemos dos conceitos tanto para a questão teórica, especialmente o Espaço de Enunciação, como para os procedimentos metodológicos de análise.

Como referido anteriormente, não adotamos um corpus pronto, mas o construímos por meio de fotografias da escrita. Os espaços de enunciação foram buscados por meio de informações prévias que já possuímos, como por exemplo, de que há língua alemã escrita em locais públicos como cemitérios, documentos de igrejas e museu municipal. E tivemos informações por meio de indicações de moradores locais, para estabelecer o contato com famílias que preservam a escrita da língua de imigração em seus lares. 
Para pensar a fotografia como objeto que constitui o nosso corpus enquanto materialidade de registro dos enunciados, nos apoiamos em Brust (2013), que em sua dissertação de mestrado pensa a constituição do documento fotográfico a partir das definições de fotografia e documento. Em um movimento inicial, o documento fotográfico é uma perspectiva para se pensar os espaços de enunciação e a memória da língua, pois de acordo com Brust (2013, p.79) "[...] se fotografia é o registro de uma imagem, o documento fotográfico a que nos referimos é o que atesta, pela fixação de uma imagem, a existência de algo [...]”, no caso, os espaços de enunciação em que circula a língua de imigração alemã em sua forma escrita. Assim, o conceito de documento fotográfico funciona em virtude de que as fotografias são de enunciados de língua escrita, ou seja, de certo modo se constituem como memória documental de uma língua.

Para este movimento analítico, recortamos três fotografias de enunciados em língua de imigração alemã, que configuram seu funcionamento semântico em espaços de enunciação público e privado. Como método de eleger os enunciados a serem analisados, adotamos o procedimento de sondagem, que acordo com Guimarães (2018, p.75) consiste em um "[...] modo de eleger enunciados decisivos a serem estudados a partir de uma pergunta, de uma questão [...]”. E a nossa questão foi observar a temática discursiva mais recorrente nos enunciados, e esta foi o discurso religioso.

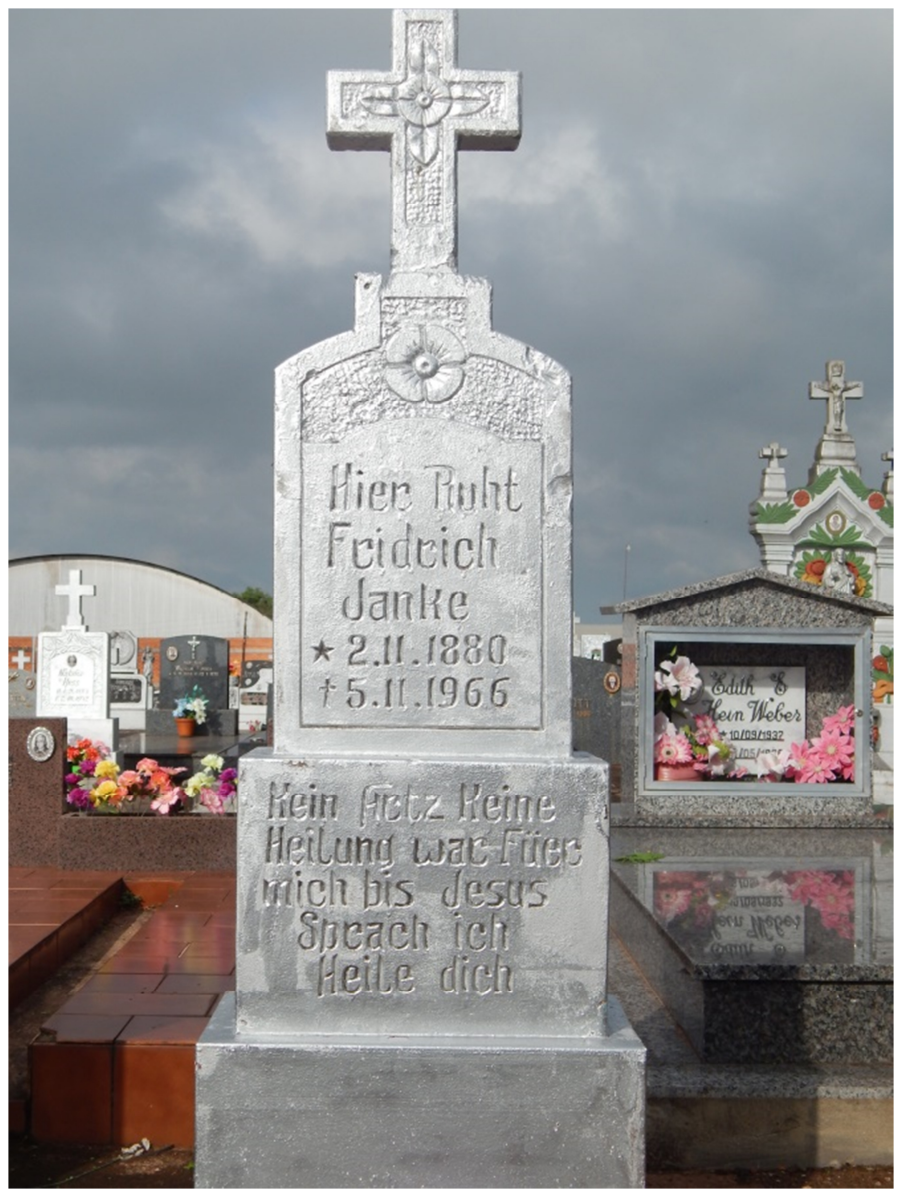

Figura 1: Foto da Sequência Enunciativa 1

Sequência Enunciativa 1 (SE1): "Nem médico e nem cura havia para nós, até que Jesus falou “Eu curo vocês””. (Tradução nossa). 
A SE1 está presente em uma lápide do cemitério da sede do município de Novo Machado, na região noroeste do Estado do Rio Grande do Sul, lugar em que há ocorrências de epitáfios escritos em língua de imigração alemã entre os anos de 1932 e 2000 . Há uma disputa de sentidos políticos neste espaço de enunciação, o que segundo Guimarães (2018) resulta na divisão do sentido.

O espaço de enunciação abarca o funcionamento de um sentido que divide o sujeito, pois há um enunciado em língua alemã inscrito em um túmulo de um cemitério localizado no Brasil, onde a língua oficial é o português. Assim, evidencia-se uma afirmação de pertencimento por meio da língua, endossado pela memória da religião. Dreher (1985) destaca que desde a chegada dos primeiros imigrantes alemães evangélicos, no século XIX, uma das prioridades foi estabelecer uma comunidade de fé, mesmo sem a presença de uma instituição eclesiástica superior capaz de coordenar e supervisionar as atividades religiosas. Assim, conforme Altmann (1994), boa parte das igrejas fundadas em comunidades de imigrantes alemães eram independentes e autônomas, uma vez que não possuíam vínculos com a tutela de igrejas do Estado.

A fé dos imigrantes alemães e seus descendentes era praticada no âmbito privado, ou seja, no seio familiar, e nos espaços públicos, como podemos observar na inscrição da lápide. A escolha da língua em que será escrito o enunciado do epitáfio se configura em uma escolha política que é atravessada por um lugar de memória, e neste caso, a religião funciona como o elemento central dessa memória que movimenta os sentidos.

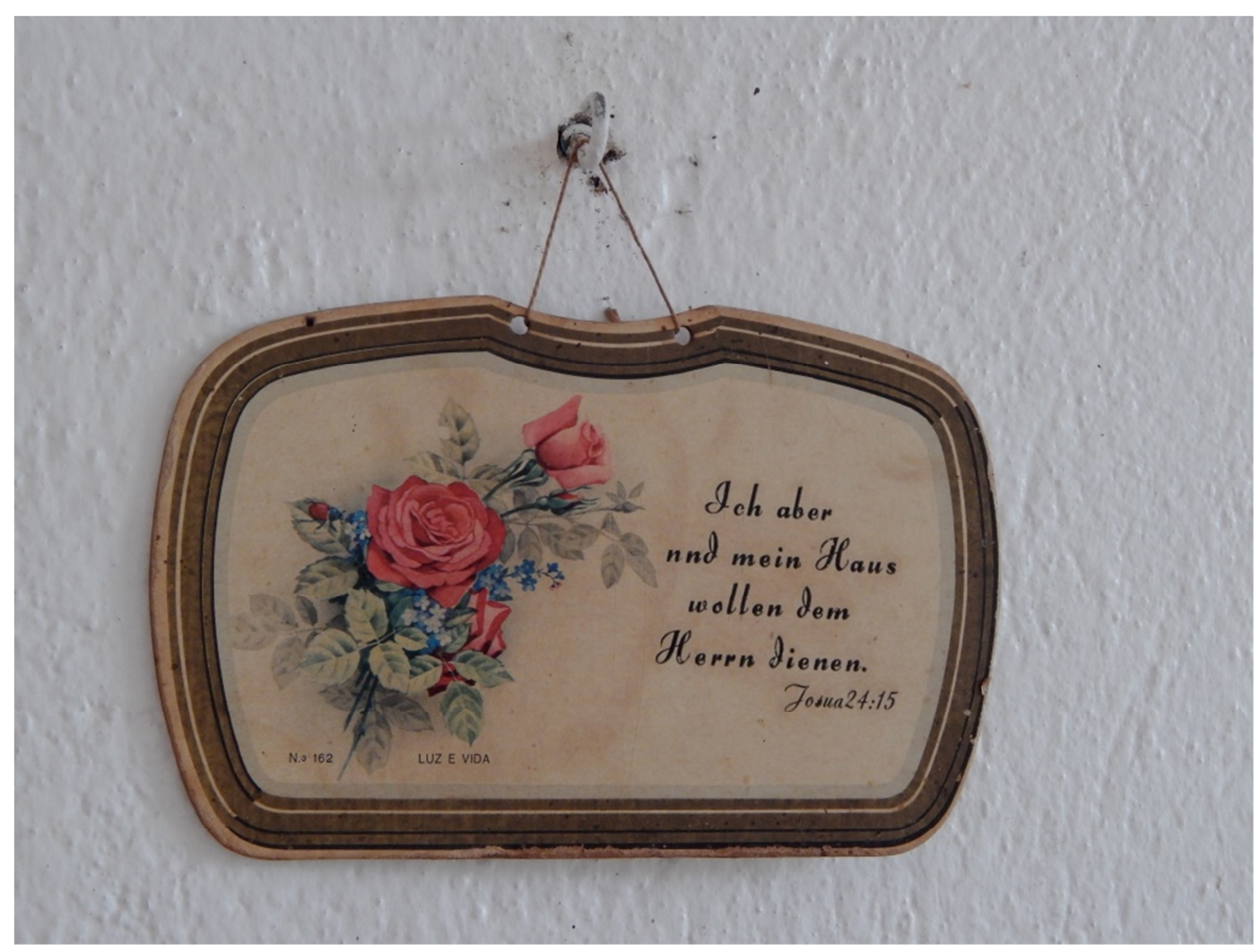

Figura 2: Foto da Sequência Enunciativa 2

Sequência Enunciativa 2 (SE2): "Eu e a minha casa queremos servir ao Senhor. Josué 24:15" (Tradução nossa). 
A SE2 consiste em um enunciado de um quadro de parede em uma casa de descendentes de imigrantes alemães, e apresenta um versículo bíblico. O movimento de sentidos denota a presença da fé e da religião no espaço de enunciação privado, representado pelo lar.

Observa-se que mesmo habitando na nova pátria, já instalados em solo brasileiro há muitos anos, os vínculos com a língua materna se mantém estreitos. Payer (2006, p.136) explica como se dá a rede de relações do sujeito com a língua quando ele vive em um local em que a sua língua materna difere da língua nacional.

Considerando a situação em que não há coincidência entre a língua materna de um sujeito e aquela que ele deve falar como língua nacional, a relação entre o "singular" da rede que constitui o sujeito (o cultural, o local) e a "rede maior" em que ela é tomada (nacional) será muito menos linear. (PAYER, 2006, p.136)

A SE2 consiste em um espaço de enunciação privado atravessado por uma memória da religião cristã. A inscrição do versículo bíblico no quadro da parede da casa constitui uma espécie de rememoração, de repetição dos sentidos que estão no interdiscurso (GUIMARÃES, 2018). O enunciado é fiel ao texto que está na Bíblia, mas uma vez recortado e inscrito no quadro, carrega sentidos que permanecem e concomitantemente novos sentidos, pois funciona semanticamente como um texto que diz algo sobre a casa, a família, que reside na casa. Um lar de pessoas cristãs que tem o propósito de servir ao Senhor, ou seja, viver conforme a vontade de Deus, e esta expressão de fé se dá por meio da língua materna dos sujeitos, o alemão.

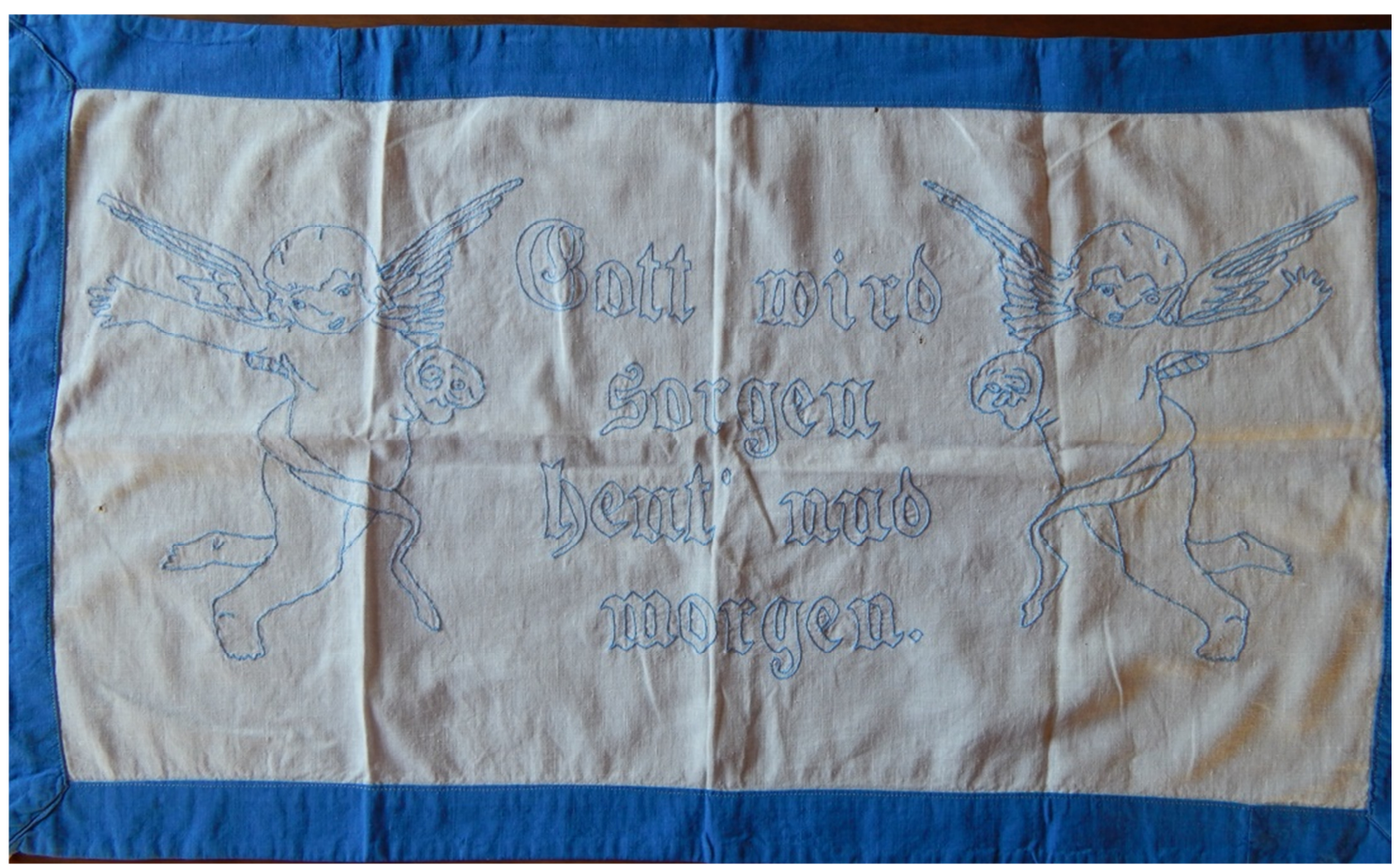

Figura 3: Foto da Sequência Enunciativa 3

Sequência Enunciativa 3 (SE3): "Deus vai prover hoje e amanhã” (Tradução nossa). 
O espaço de enunciação da SE3 é um wandschoner, conhecido tradicionalmente como "pano ou protetor de parede", e de uso bastante comum em famílias de imigrantes alemães e seus descendentes. O enunciado "Deus vai prover hoje e amanhã" expressa a fé cristã da família, mas diferentemente da SE2, não se constitui em um versículo bíblico, é um enunciado atravessado por um saber religioso intrínseco ao grupo, uma memória que se formula a partir desse saber.

Gaelzer (2014, p.62) afirma que "Os imigrantes da mesma forma que organizavam as escolas, cujo objetivo era perpetuar a preservação da língua, também organizavam suas atividades religiosas.”. Ou seja, a importância da religião se equiparava à importância da educação, e em decorrência disso recebia um lugar de destaque nos espaços públicos e nos espaços de enunciação privados.

Muitas famílias acreditavam que os wandschoners funcionavam como protetores do lar, uma espécie de crença que foi repassada de geração em geração, até que se tornou uma tradição cultural das famílias de descendentes de imigrantes alemães. Mesmo que os panos de parede não estivessem mais relacionados à crença da proteção do lar, em sua maioria, expressavam a confissão de fé das famílias.

\section{Considerações finais}

A partir deste estudo observamos dois espaços de enunciação, o público e o privado que são atravessados pelo funcionamento político da religião como memória da língua e lugar da própria memória. Expressar a fé no último enunciado que marca a passagem de um sujeito pela face da terra, ou seja, no epitáfio; bem como, inscrevê-la nas paredes da casa, seja em quadros ou panos de parede, consiste em atribuir-lhe um funcionamento político na vida dos sujeitos bastante significativo.

No espaço público, última morada do sujeito, ou no mais íntimo do lar, em que se tecem a maioria dos capítulos da existência do sujeito em vida; a fé se faz presente, e marca essa presença de uma forma peculiar, na língua materna. Na parede de casa ou no cemitério, o enunciar em alemão é carregado de sentidos inerentes à língua.

Os enunciados presentes nesses lugares de enunciação possuem um significado de muito peso para os sujeitos, e o fato de serem escritos em língua materna, o alemão, acentua o seu significado. O que vai ao encontro com os pressupostos de Payrer (2006) ao afirma que sujeito e língua são constitutivos, e neste caso, o sujeito imigrante e descendente de alemães mostra-se como atravessado e constituído politicamente pelas memórias da língua materna.

\section{Referências}

ALTMANN, W. Lutero e libertação: releitura de Lutero em perspectiva Latino-Americana. São Paulo: Ática; São Leopoldo: Sinodal, 1994.

BENVENISTE, E. Problemas de Linguística Geral II. Campinas: Pontes, 2006.

BOlOGNINI, C. Z.; PAYER, M. O. Linguas de imigrantes. Cienc. Cult. vol.57 n.2. São Paulo, 2005. Disponível em: 
<http://cienciaecultura.bvs.br/scielo.php?pid=S000967252005000200020\&script=sci_arttext $>$ Acesso em: 14 jan. 2020

BRUST, V. O efeito "Chapéu de Clementis": Imagens do sujeito imigrante italiano na Quarta Colônia. 2013. 174 p. Dissertação de Mestrado - Universidade Federal de Santa Maria, Santa Maria, 2013.

CAMPOS, C. M. A política da lingua na era Vargas. Campinas, SP: Editora da Unicamp, 2006.

DREHERM M. N. Tentativa de teologia protestante em uma igreja de imigrantes no Brasil. In: Simpósio de História da Igreja. São Leopoldo: Sinodal, pp. 35-50, 1986.

GUIMARÃES, E. Enunciação, Língua, Memória. Revista da ANPOLL, n², pp.27-33, 1996.

GUIMARÃES, E. Semântica: enunciação e sentido. Campinas, SP: Pontes Editores, 2018.

GUIMARÃES, E. Os limites do sentido. Campinas: Pontes, 2002.

MARIANI, B. Colonização Lingüistica. Campinas: Pontes, 2004.

ORLANDI, E. P. Lingua e conhecimento linguístico: para uma história das ideias linguísticas no Brasil. 2.ed. São Paulo: Cortez, 2013.

ORLANDI, E. P. Análise de Discurso: princípios e procedimentos. 4a ed. Campinas: Pontes, 2002.

PAYER, M. O. Memória da língua: imigração e nacionalidade. São Paulo: Escuta, 2006.

PARCIANELLO, J. F. O dizer na e sobre a língua de sujeitos descendentes de imigrantes italianos e a fronteira enunciativa. 2011. 115 f. Dissertação (Mestrado em Letras). Universidade Federal de Santa Maria, Santa Maria, 2013. Disponível em:

<http://cascavel.ufsm.br/tede//tde_busca/arquivo.php?codArquivo=3596>. Acesso em: 25 jan. 2020.

PRIEBE, G.; SCHROEDER, N. Novo Machado conta a sua História. 2 ed. Novo Machado: 2005.

STUMPF, I.R.C. Pesquisa bibliográfica. In: DUARTE, J.; BARROS, A. (org.). Métodos e técnicas de pesquisa em Comunicação. 6 ed. São Paulo: Atlas, 2002.

TATSCH, L. Estudo enunciativo da designação da expressão Línguajar gaúcho na obra de Dante de Laytano: Reflexão sobre a noção de acontecimento. Web Revista Sociodialeto. Disponível em: <http://sociodialeto.com.br/edicoes/16/10012014013808.pdf〉. Acesso em: 20. Fev.2020.

WEBER, A. Politica de línguas e mídia no mercosul: um estudo enunciativo de jornais de fronteira. Tese de Doutorado. Santa Maria, RS, 2013.

Recebido em: 21/05/2020

Aceito em: 03/07/2020 